\title{
Stereotactic radiotherapy for wet age-related macular degeneration: current perspectives
}

\author{
This article was published in the following Dove Press journal: \\ Clinical Ophthalmology \\ 28 September 2015 \\ Number of times this article has been viewed
}

\author{
James E Neffendorf \\ Timothy L Jackson \\ Department of Ophthalmology, \\ School of Medicine, King's College \\ London, London, United Kingdom
}

Correspondence: Timothy L Jackson Department of Ophthalmology, Normanby Building, King's College Hospital, Denmark Hill, London SE5 9RS, United Kingdom

Tel +442032993385

Fax +44 2032993738

Email t.jackson I@nhs.net

\begin{abstract}
Neovascular age-related macular degeneration is a leading cause of blindness in the developed world. Currently, the treatment of choice is intravitreal injections of anti-VEGF medications. These require frequent dosing, up to monthly, and impose a substantial burden on patients and the health economy. Ionizing radiation was proposed as a possible treatment for age-related macular degeneration due to its anti-inflammatory and anti-fibrotic properties. Stereotactic radiotherapy is an outpatient-based radiotherapy platform that provides stereotactic application of low energy X-ray to the retina in three highly collimated beams that cross the inferior sclera to overlap at the macula. A randomized, double-masked, sham-controlled trial of 230 patients (INTREPID) showed that a single dose of stereotactic radiotherapy significantly reduces the number of intravitreal anti-VEGF injections needed over 2 years. A larger randomized controlled trial (STAR) is underway.
\end{abstract}

Keywords: wet age-related macular degeneration, radiation therapy, stereotactic radiotherapy, vascular endothelial growth factor

\section{Introduction}

Age-related macular degeneration (AMD) is the leading cause of blindness in individuals over 50 years old in developed nations. ${ }^{1,2}$ It can have a profound impact on quality of life, and affects more than 500,000 people in the UK alone. ${ }^{3}$ Approximately $10 \%$ of those affected have the neovascular "wet" form of the disease, which is clinically more aggressive and destructive, but also more amenable to treatment. The mainstay of treatment for wet AMD is chronic treatment with anti-VEGF drugs, with regular, ongoing clinical review from the point of diagnosis. Given the rapidly aging population and constrained health care budgets, there is an unmet need for a more cost effective treatment, and one that does not involve such an intensive treatment regimen.

Wet AMD is characterized by the growth of abnormal new blood vessels in a process called choroidal neovascularization. These vessels originate from the choriocapillaris, and traverse Bruch's membrane into the sub-retinal pigment epithelial and sub-retinal spaces. The new vessels have poor structural integrity and tend to leak, resulting in hemorrhage and edema, which results in degradation of visual function. This process is often irreversible, leading to scarring and ultimately permanent loss of central vision.

At present, the main strategy for the treatment of wet AMD is via modulators of VEGF. ${ }^{4}$ There are several anti-VEGF drugs available, including pegaptanib, ranibizumab, bevacizumab, and aflibercept. Pivotal studies demonstrated significant visual improvements using ranibizumab, given on a monthly basis. ${ }^{5,6}$ The Comparison of AMD Treatments Trials (CATT) study, analyzing visual outcomes with bevacizumab and ranibizumab therapy, 
found no significant difference between the two agents at 1 and 2 years, when given at the same dosing regimen. Additionally, both agents showed better visual outcomes when administered monthly, compared with "as required" (pro re nata [PRN]) dosing. ${ }^{7,8}$ Monthly dosing imposes a significant economic and personal burden on the health care sectors and patients respectively, and therefore a less intensive treatment modality would be desirable. Furthermore, each injection carries small risks, such as endophthalmitis and retinal detachment, and therefore a reduction in their frequency, without compromising efficacy, would be a substantial advance. ${ }^{9}$

\section{Radiation and neovascular AMD}

Radiation is defined as the outward emission of energy from a central source and is commonly used in medical practice. Most commonly, it is used as a diagnostic tool, for example with plain radiographs and computed tomography. Secondly, radioactive substances can be introduced inside the body and their release of radiation used for therapeutic purposes such as radioisotope treatment of hyperthyroidism. Additionally, high powered X-ray machines or radioactive sources can be used to deliver radiotherapy when they are aimed into the body from an external source.

Radiation is used to selectively and irreversibly damage the DNA of target cells which prevents further replication. Cells that are rapidly dividing, or of abnormal morphology, undergo apoptosis following radiation therapy, whereas non-dividing cells are better able to repair the damage and remain structurally intact. ${ }^{10}$

Treatment with radiation can be divided into two categories. Brachytherapy, known as internal radiotherapy, refers to a radiation source being directly inserted or placed next to the target site surgically, for example in the treatment of prostate tumors. ${ }^{11,12}$ Teletherapy uses an external source to channel radiation into a fine beam that is projected to the target tissue. Teletherapy is commonly utilized in oncology, particularly with breast malignancy. ${ }^{13}$ One form of teletherapy is stereotactic radiotherapy (SRT), where multiple narrow beams of radiation can be used to target small well defined areas with precision.

Some radioactive sources, for example potassium-40 and strontium-90, emit high-speed electrons or positrons in a process called beta decay. The potential benefit of beta decay in ophthalmology was predicted in animal models in 1987, when cultured monkey ocular fibroblasts were shown to undergo rapidly reduced proliferation following exposure in vitro. ${ }^{14}$ Since then, there have been reports of radiation used as an adjunctive treatment for pterygium and glaucoma filtration surgery..$^{10,15}$

Radiation can also be used to treat wet AMD, since this disease is caused by abnormal cell proliferation and radiation preferentially damages these cells. ${ }^{16-19}$ However, the introduction of anti-VEGF therapy produced better visual outcomes than radiation and therefore the use of radiation diminished. ${ }^{5,20}$ Studies are now investigating whether radiation might have a role as an adjuvant to anti-VEGF therapy. This adjuvant approach is supported by results in other branches of medicine, where combined treatment produces better results than either treatment modality individually, for example alongside chemotherapy in breast cancer. ${ }^{21}$ Anti-VEGF agents have a rapid onset of action, but they typically require long-term, repeated dosing to maintain their therapeutic effect. As radiotherapy has a delayed effect, but a long duration of action, it may work synergistically with anti-VEGF therapy.

\section{Epimacular brachytherapy}

Epimacular brachytherapy (EMB) was designed as a way of precisely delivering radiation to the macula in patients with wet AMD. ${ }^{22}$ The EMB device (NeoVista Inc., Fremont, CA, USA) contained a strontium-90/yttrium-90 source that delivered radiation to the macula using an intraocular probe during vitrectomy. The Macular Epiretinal Brachytherapy in Treated Age-related Macular Degeneration (MERITAGE) study was an international, multicenter, prospective, interventional, non-controlled clinical trial of 53 patients with previously treated, active disease. All patients underwent vitrectomy with EMB, and received PRN ranibizumab treatment, governed by pre-defined retreatment criteria. At 1 year follow-up, $81 \%$ of participants lost fewer than 15 Early Treatment of Diabetic Retinopathy Study (ETDRS) letters whilst only 3.49 anti-VEGF retreatments were required. ${ }^{23}$ Secondary outcomes showed a mean best corrected visual acuity change of -4.0 ETDRS letters and a small increase in optical coherence tomography central retinal thickness of $50 \mu \mathrm{m}$, that failed to reach significance. Subgroup analysis revealed that predominantly classic lesions did best, with a mean gain of 1.5 ETDRS letters and mean center point thickness decreased by $43 \mu \mathrm{m} .{ }^{24}$ The 2 -year data on the same cohort showed more frequent ranibizumab retreatment than in year 1 , increasing from 0.29 injections per month in months $0-12$, to 0.44 injections per month in months $13-24$, however both were less than occurred pre-radiation ( 0.50 injections per month). ${ }^{25}$ Two participants developed possible nonproliferative radiation retinopathy over 24-month follow-up, 
but this did not negatively affect their vision. There were no other adverse events attributed to radiation therapy. ${ }^{25}$

The Choroidal Neovascularization Secondary to AMD Treated with Beta Radiation Epiretinal Therapy (CABERNET) trial was a large, pivotal, multicenter, randomized controlled trial investigating the use of EMB in 495 treatment naïve patients. At 24 months, $77 \%$ and $90 \%$ of the EMB group and control group lost fewer than 15 ETDRS letters respectively. As such the trial failed to meet its non-inferiority endpoint. Furthermore, $16 \%$ of the EMB group versus (vs) $26 \%$ of the control group gained more than 15 letters. There was a reduction in the number of injections in the EMB group, at 6.2, compared to 10.4 in the control group, although this comparison did not necessarily indicate a reduced demand for anti-VEGF therapy in the radiation arm, as this arm had fewer mandated injections. Although 3\% of the EMB group had mild non-proliferative radiation retinopathy, all these cases lost fewer than 15 ETDRS letters with a mean gain of 4.4 letters at 24 months. Further, the radiation changes were often relatively subtle, and substantially different to the clinical picture observed with high dose radiation for ocular tumors. The participants with retinopathy had better outcomes than those who did not, and overall safety was deemed acceptable. ${ }^{26,27}$

In summary, the encouraging early clinical trials of EMB for treatment naïve disease were not replicated in a Phase III pivotal trial (CABERNET), and therefore its use in this setting is unproven. ${ }^{28}$ A pivotal study in previously treated disease (MERLOT; ClinicalTrials.gov identifier NCT01006538) is expected to report soon.

\section{SRT}

\section{Introduction}

In order to improve the delivery of radiation to the neovascular lesion, a US biotechnology company (Oraya Therapeutics, Newark, CA, USA) developed an SRT device (IRay) designed specifically to treat wet AMD in a single treatment session. The device uses low-voltage X-rays to generate three separate beams of highly collimated radiation that pass through the inferior sclera at different angles to overlap at the macula in a $4 \mathrm{~mm}$ diameter treatment zone (Figures 1 and 2). This is designed to minimize the radiation exposure to surrounding healthy tissue, whilst giving a high dose to the desired target. Unlike EMB, SRT does not require vitrectomy and therefore gives a more practical method for radiation delivery. Additionally, this may be advantageous as vitrectomy reduces the half-life of intravitreal drugs, so that any remaining disease activity may be hard to control

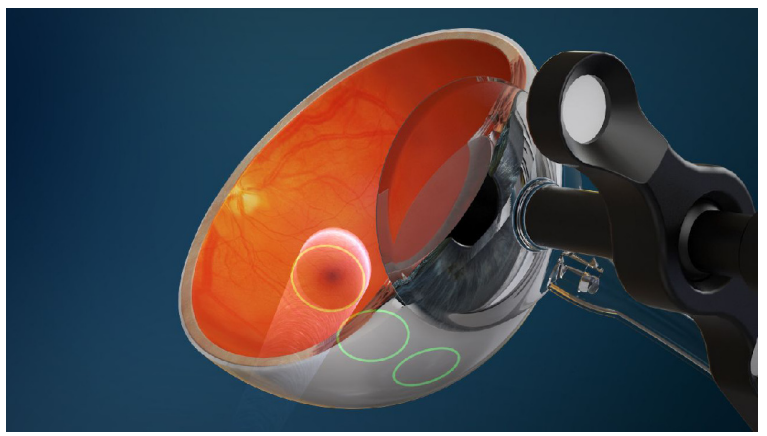

Figure I Diagram showing the location of three collimated beams of radiation passing through the inferior sclera (green circles) to avoid the crystalline lens, during stereotactic radiotherapy.

Note: Image courtesy of Oraya (Oraya Therapeutics, Newark, CA, USA).

with anti-VEGF agents. ${ }^{29}$ Furthermore, with IRay, the entire $4 \mathrm{~mm}$ treatment zone receives $90 \%$ of the intended dose, whereas with EMB the dose declines exponentially with distance from the source, meaning larger lesions received lower doses peripherally. ${ }^{30}$

\section{Details of the procedure}

The SRT machine is an outpatient radiotherapy platform that measures approximately 1.5 meters $\times 2$ meters and is designed for use in a standard medical office, without the need for added room radiation shielding (Figure 3). ${ }^{31,32}$ The clinician is separated from the patient and protected from radiation by a lead screen. Due to the focused nature of the low-energy beams, no intrinsic radiation protection such as lead aprons are required for the patient or operator..$^{33}$ The machine has a number of key components in order to accurately and safely

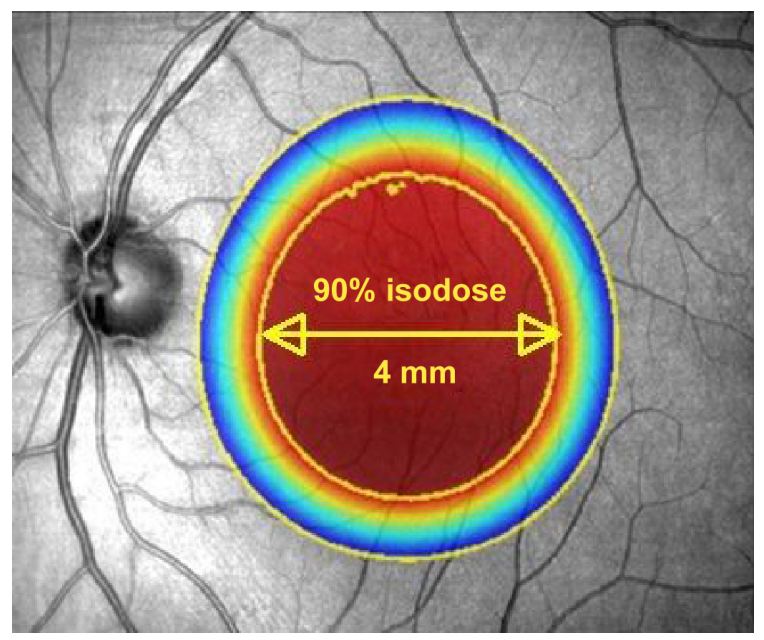

Figure 2 Illustration to show the attenuation effect of the three collimated beams to deliver $90 \%$ of the desired radiation dose to a $4 \mathrm{~mm}$ diameter at the macula. Notes: Outside the $4 \mathrm{~mm}$ diameter zone, the radiation delivered diminishes rapidly. Image reproduced with modification, courtesy of Oraya (Oraya Therapeutics, Newark, CA, USA). 


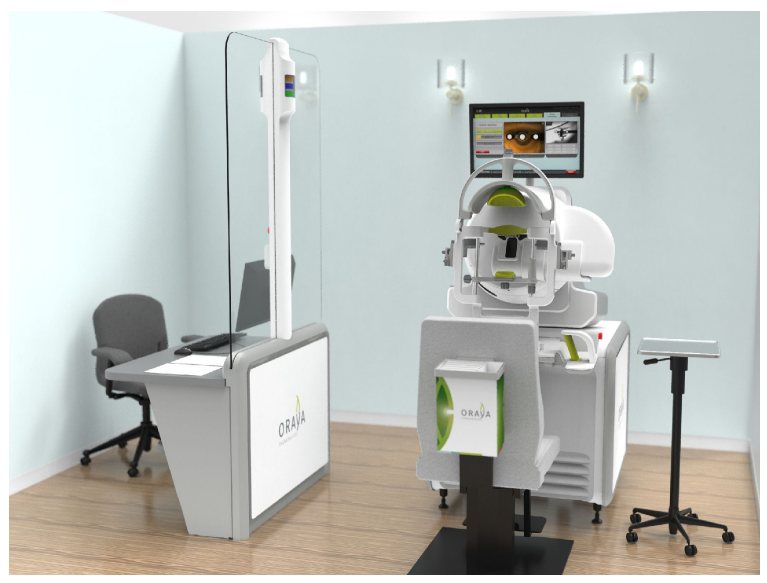

Figure 3 The room set-up of the IRay system.

Notes: The operator controls (left) are separated from the radiotherapy machine (right) and patient by a lead-lined glass screen, allowing the operator to view the patient. Image courtesy of Oraya (Oraya Therapeutics, Newark, CA, USA).

deliver treatment. A low energy X-ray tube produces three narrow collimated beams, which are designed to pass through the inferior sclera, avoiding the crystalline lens, and focus on the macula. Built-in computer software is used to robotically position the treatment based on the axial length of the eye that is entered into the machine by the clinician.

The patient sits normally with their chin placed on a chin rest in order to receive the treatment. A sterile, disposable contact lens is placed centrally on the cornea and sclera, and kept in place by a light suction mechanism (Figure 4). A small retractor is used to retract the lower eyelid and expose the inferior sclera to the radiation beams. The radiation delivery then commences and treatment usually takes approximately 10 minutes. The machine uses an eye tracking device to continuously monitor the eye position, and radiation treatment is automatically shut down if excessive eye movement is detected.

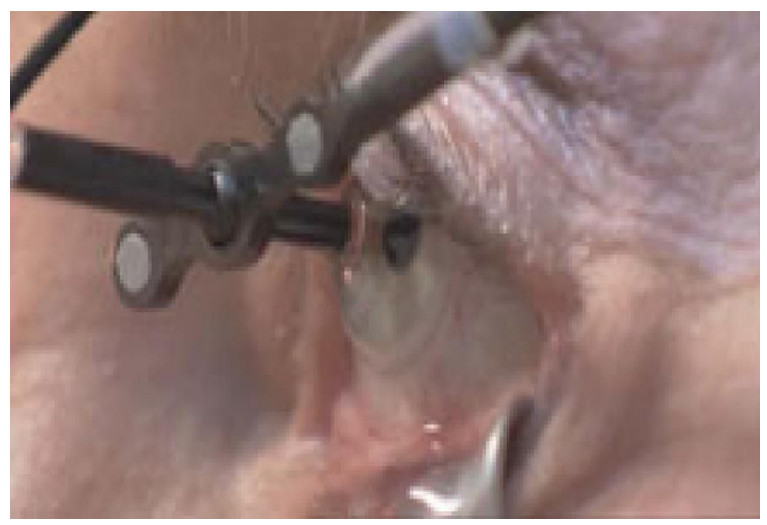

Figure 4 A contact lens, with light suction mechanism, is used to keep the eye in position during treatment.

Note: Copyright @ 201 I. Petrarca R, Jackson TL. Radiation therapy for neovascular age-related macular degeneration. Clin Ophthalmol. 201 I;5:57-63. ${ }^{22}$

\section{Efficacy}

Two Phase I studies were carried out to assess the safety and preliminary efficacy of different doses of SRT. ${ }^{34,35}$ Radiation doses of 16 Gy and 24 Gy in conjunction with ranibizumab produced improvement in visual acuity at 6 months. There were no safety concerns, and in particular no cases of radiation retinopathy, although follow-up was only reported at 6 months.

Following on from the promising Phase I study results, the multicenter, randomized, double-masked, sham-controlled IRay plus Anti-VEGF Treatment For Patients with Wet AMD (INTREPID) trial investigated the use of SRT for previously treated wet AMD (ClinicalTrials.gov identifier NCT01016873). ${ }^{36}$ A total of 230 patients were randomized 2:1:2:1 to $16 \mathrm{~Gy}$, sham $16 \mathrm{~Gy}, 24 \mathrm{~Gy}$, or sham $24 \mathrm{~Gy}$-all arms received PRN ranibizumab based on pre-defined retreatment criteria. At 1 year follow-up, both the SRT groups (16 Gy and 24 Gy) received significantly fewer ranibizumab injections than the sham arms (2.64, 2.43 and 3.74 respectively), thus meeting the study's primary end point. ${ }^{36}$ The effect on reduction of number of injections was sustained at 2 years $(4.5,5.4$ and 6.6 respectively) with statistical significance for the $16 \mathrm{~Gy}$ group $(P=0.008)$. Also, $15 \%$ of those receiving SRT required no further ranibizumab injections over 2 years. ${ }^{37}$

The $16 \mathrm{~Gy}, 24 \mathrm{~Gy}$, and sham arms gained 0 or more letters in $32 \%, 43 \%$, and $38 \%$ of eyes respectively, with $68 \%$, $75 \%$, and $79 \%$ losing fewer than 15 letters, respectively at 24 months. A pre-defined year 1 subgroup analysis showed SRT was more effective in lesions $\leq 4 \mathrm{~mm}$ in greatest linear dimension, which correlates with the $4 \mathrm{~mm}$ diameter treatment zone. Those with macular volumes greater than the median value of $7.4 \mathrm{~mm}^{3}$ also had better outcomes with radiotherapy. The presence of both a greatest linear dimension $\leq 4 \mathrm{~mm}$ and a macular volume $\geq 7.4 \mathrm{~mm}^{3}$ was associated with a $55 \%$ reduction in the number of ranibizumab injections compared to sham (2.08 vs $4.60 ; P=0.0002)$, better visual outcome ( 2.18 vs -3.15 letters; $P=0.0284$ ) and superior structural outcome $(-122.6 \mu \mathrm{m}$ vs $-51.5 \mu \mathrm{m}$ reduction in mean central subfield thickness on optical coherence tomography; $P=0.027) .{ }^{38}$

Based on these subgroup analyses it seems reasonable to use this device only when the patient has significant active leakage, and to avoid any patient whose lesion extends beyond the $4 \mathrm{~mm}$ treatment zone, which is centered at the fovea.

Strengths of the INTREPID study are its randomized, double-masked, sham-controlled design. Weaknesses include the fact that it was not designed to establish efficacy beyond year 1; the visits at year 2 and 3 were designed to assess safety. After year 1 the anti-VEGF treatment was dictated 
by the prevailing standard of care across a range of sites and countries. The study was designed to determine if radiotherapy reduces the number of injections, and not to detect a difference in visual acuity outcomes.

\section{Safety}

In terms of safety, over 24 months, there were similar numbers of adverse events and serious adverse events in both arms. Eighteen participants in the radiotherapy arms were identified as having microvascular abnormalities (MVAs) by a panel of experts, of which two were considered likely to have affected vision. These two cases lost 46 letters and 41 letters respectively, with 13 and eight $P R N$ ranibizumab injections needed respectively, but it was concluded that the underlying AMD process was likely to have been the main contributor to visual loss in each case. All other 16 cases had MVAs which were extra-foveal, and ten of these were located outside the $4 \mathrm{~mm}$ treatment area. Overall, the mean visual change in the 18 eyes with radiation attributed MVAs was similar to the mean change in the total cohort receiving SRT. ${ }^{37}$

\section{Conclusion}

The clinical, financial, and social burden of AMD is substantial, and continues to rise with an aging population. It is therefore important to explore novel treatment options for the expanding cohort of patients undergoing regular intravitreal injections. Radiation has many theoretical advantages as a means of treating wet AMD, and following the encouraging results of INTREPID, a large randomized, double-masked, sham-controlled clinical trial is underway (STAR). Like INTREPID, the STAR study is designed to establish if SRT reduces the number of anti-VEGF injections that patients require, but it targets the best responder group identified in the INTREPID subgroup analysis. Unlike INTREPID, STAR is powered to determine if visual acuity is non-inferior to anti-VEGF monotherapy, and with extended safety follow-up over 4 years (ClinicalTrials.gov identifier NCT02243878).

\section{Disclosure}

Timothy L Jackson's employer has received research funding from NeoVista Inc., Oraya Therapeutics, and Novartis. The authors have no other conflicts of interest to disclose.

\section{References}

1. Congdon N, O'Colmain B, Klaver CC, et al. Causes and prevalence of visual impairment among adults in the United States. Arch Ophthalmol. 2004;122(4):477-485.

2. Pascolini D, Mariotti SP, Pokharel GP, et al. 2002 global update of available data on visual impairment: a compilation of population-based prevalence studies. Ophthalmic Epidemiol. 2004;11(2):67-115.
3. Macularsociety.org [homepage on the Internet]. The Macular Society, United Kingdom; 2013. Available from: www.macularsociety.org. Accessed July 15, 2013.

4. Wong TY, Liew G, Mitchell P. Clinical update: new treatments for age-related macular degeneration. Lancet. 2007;370(9583):204-206.

5. Rosenfeld PJ, Brown DM, Heier JS, et al. Ranibizumab for neovascular age-related macular degeneration. $N$ Engl J Med. 2006;355(14): 1419-1431.

6. Brown DM, Kaiser PK, Michels M, et al. Ranibizumab versus verteporfin for neovascular age-related macular degeneration. $N$ Engl J Med. 2006;355(14):1432-1444.

7. CATT Research Group, Martin DF, Maguire MG, et al. Ranibizumab and bevacizumab for neovascular age-related macular degeneration. N Engl J Med. 2011;364(20):1897-1908.

8. Comparison of Age-related Macular Degeneration Treatments Trials (CATT) Research Group, Martin DF, Maguire MG, et al. Ranibizumab and bevacizumab for treatment of neovascular age-related macular degeneration: two-year results. Ophthalmology. 2012; 119(7):1388-1398.

9. Falavarjani KG, Nguyen QD. Adverse events and complications associated with intravitreal injection of anti-VEGF agents: a review of literature. Eye (Lond). 2013;27(7):787-794.

10. Kirwan JF, Constable PH, Murdoch IE, Khaw PT. Beta irradiation: new uses for an old treatment: a review. Eye (Lond). 2003;17(2):207-215.

11. Barnhard HJ. Supervoltage therapy comes of age. N Engl J Med. 1958; 258(6):275-277.

12. Paulson DF. Carcinoma of the prostate: the therapeutic dilemma. Annu Rev Med. 1984;35:341-372.

13. Lenz M, Freid JR. Metastases to the skeleton, brain and spinal cord from cancer of the breast and the effect of radiotherapy. Ann Surg. 1931; 93(1):278-293.

14. Nevarez JA, Parrish RD 2nd, Heuer DK, Hajek AS, Houdek PV, Mallick KS. The effect of beta irradiation on monkey Tenon's capsule fibroblasts in tissue culture. Curr Eye Res. 1987;6(5):719-723.

15. Mead KW. Beta irradiation for recurrent pterygia. Trans Ophthalmol Soc Aust. 1956;16:101-109.

16. Chakravarthy U, Houston RF, Archer DB. Treatment of age-related subfoveal neovascular membranes by teletherapy: a pilot study. Br J Ophthalmol. 1993;77(5):265-273.

17. Reinhold HS, Buisman GH. Radiosensitivity of capillary endothelium. Br J Radiol. 1973;46(541):54-57.

18. Chakravarthy U, Mackenzie G. External beam radiotherapy in exudative age-related macular degeneration: a pooled analysis of phase I data. Br J Radiol. 2000;73(867):305-313.

19. Jaakkola A, Heikkonen J, Tommila P, Laatikainen L, Immonen I. Strontium plaque brachytherapy for exudative age-related macular degeneration: three-year results of a randomised study. Ophthalmology. 2005; 112(4):567-573.

20. Evans JR, Sivagnanavel V, Chong V. Radiotherapy for neovascular age-related macular degeneration. Cochrane Database Syst Rev. 2010(5):CD004004.

21. Ragaz J, Jackson SM, Le N, et al. Adjuvant radiotherapy and chemotherapy in node-positive premenopausal women with breast cancer. N Engl J Med. 1997;337(14):956-962.

22. Petrarca R, Jackson TL. Radiation therapy for neovascular age-related macular degeneration. Clin Ophthalmol. 2011;5:57-63.

23. Dugel PU, Petrarca R, Bennett M, et al. Macular epiretinal brachytheraoy in treated age-related macular degeneration: MERITAGE study: twelve-month safety and efficacy results. Ophthalmology. 2012;119(7): 1425-1431.

24. Petrarca R, Dugel PU, Nau J, Slakter JS, Jaffe GJ, Jackson TL. Macular epiretinal brachytherapy in treated age-related macular degeneration (MERITAGE): month 12 optical coherence tomography and fluorescein angiography. Ophthalmology. 2013;120(2):328-333.

25. Petrarca R, Dugel PU, Bennett M, et al. Macular Epiretinal Brachytherapy in treated Age-Related Macular Degeneration (MERITAGE) Month 24 Safety and Efficacy Results. Retina. 2014;34(5):874-879. 
26. Dugel PU, Bebchuk JD, Nau J, et al. Epimacular brachytherapy for neovascular age-related macular degeneration: a randomized, controlled trial (CABERNET). Ophthalmology. 2013;120(2):317-327.

27. Jackson TL, Dugel PU, Bebchuk JD, et al. Epimacular Brachytherapy for Neovascular Age-Related Macular Degeneration (CABERNET): Fluoroscein Angiography and Optical Coherence Tomography. Ophthalmology. 2013;120(8):1597-1603.

28. Casaroli-Marano RP, Alforja S, Giralt J, Farah ME. Epimacularbrachytherapy for wet AMD: current perspectives. Clin Ophthalmol. 2014;8: 1661-1670.

29. Beer PM, Bakri RJ, Singh RK, Liu W, Peters GB 3rd, Miller M. Intraocular concentration and pharmacokinetics of triamcinolone acetonide after a single intravitreal injection. Ophthalmology. 2003;110(4):681-686.

30. Petrarca R, Richardson M, Douiri A, et al. Safety testing of epimacular brachytherapy with microperimetry and indocyanine green angiography: 12-Month Results. Retina. 2013;33(6):1232-1240.

31. Hanlon J, Lee C, Chell E, et al. Kilovoltage stereotactic radiosurgery for age-related macular degeneration: assessment of optic nerve dose and patient effective dose. Med Phys. 2009;36(8):3671-3681.

32. Moshfeghi DM, Kaiser PK, Gertner M. Stereotactic low-voltage x-ray irradiation for age-related macular degeneration. Br JOphthalmol. 2011; 95(2):185-188.
33. Orayainc.com [homepage on the Internet]. USA: Oraya Therapeutics, Inc.; 2014. Available from: http://www.orayainc.com. Accessed December 6, 2014.

34. Canton VM, Quiroz-Mercado H, Velez-Montoya R, et al. 16 Gy lowvoltage x-ray irradiation with ranibizumab therapy for AMD: 6-month safety and functional outcomes. Ophthalmic Surg Lasers Imaging. 2011; 42(6):468-473.

35. Canton VM, Quiroz-Mercado H, Velez-Montoya R, et al. 24-Gy lowvoltage X-ray irradiation with ranibizumab therapy for neovascular AMD: 6-month safety and functional outcomes. Ophthalmic Surg Lasers Imaging. 2012;43(1):20-24.

36. Jackson TL, Chakravarthy U, Kaiser PK, et al. Stereotactic radiotherapy for neovascular age-related macular degeneration: 52-week safety and efficacy results of the INTREPID study. Ophthalmology. 2013;120(9): 1893-1900.

37. Jackson TL, Chakravarthy U, Slakter JS, et al. Stereotactic Radiotherapy for Neovascular Age-Related Macular Degeneration: Year 2 Results of the INTREPID Study. Ophthalmology. 2015;122(1):138-145.

38. Jackson TL, Shusterman EM, Arnoldussen M, Chell E, Wang K, Moshfeghi DM. Stereotactic Radiotherapy for wet age-related macular degeneration (INTREPID): Influence of baseline characteristics on clinical response. Retina (Philadelphia, Pa.). 2015;35(2):194-204.
Clinical Ophthalmology

\section{Publish your work in this journal}

Clinical Ophthalmology is an international, peer-reviewed journal covering all subspecialties within ophthalmology. Key topics include: Optometry; Visual science; Pharmacology and drug therapy in eye diseases; Basic Sciences; Primary and Secondary eye care; Patient Safety and Quality of Care Improvements. This journal is indexed on

\section{Dovepress}

PubMed Central and CAS, and is the official journal of The Society of Clinical Ophthalmology (SCO). The manuscript management system is completely online and includes a very quick and fair peer-review system, which is all easy to use. Visit http://www.dovepress.com/ testimonials.php to read real quotes from published authors. 